\title{
Aspectos de análise
}

\section{termomecânica $\epsilon$ de rigidez de concretos para torres eólicas}

\begin{tabular}{c}
\hline ANTÔNIO EDUARDO BEZERRA CABRAL \\
\hline AMANDA MOREIRA LIMA MACHADO \\
\hline LUCAS FEITOSA DE ALBUQUERQUE LIMA BABADOPULOS \\
\hline Programa de Pós-Graduação em Engenharia Civil: Estruturas E Construção CIVIL (PEC)
\end{tabular}

Universidade Federal do Ceará (UFC)

\section{RESUMO}

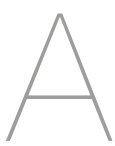

spectos termomecânicos e de rigidez dos concretos utilizados nos blocos de fundações e nos segmentos de torres eólicas são importantes devido ao risco de fissuração, à formação de etringita tardia e às alterações na frequência de vibração das torres eólicas, podendo causar sérios danos a elas. Este artigo apresenta e exemplifica as etapas, os parâmetros intervenientes e os resultados da simulação de estudo termomecânico de um bloco de fundação de torre eólica, tendo como resultado a evolução da temperatura do concreto e seu índice de fissuração. Além disso, apresenta recomendações práticas de lançamento do concreto e da escolha de pontos de monitoramento. $\mathrm{O}$ artigo retrata ainda a importância do módulo de elasticidade enquanto parâmetro de controle do concreto de segmentos de torres eólicas, considerando estudos que apontam a disparidade entre o módulo real, obtido por meio de ensaios em laboratório, e o estimado por meio da ABNT NBR 6118:2014, em função dos tipos de agregados utilizados.

\section{INTRODUÇÃO}

A produção de energia elétrica a partir da energia mecânica gerada pelos ventos está se mostrando eficaz e vem apresentando índices de uso ascendentes em vários países, com destaque para o Brasil, em especial para a região Nordeste. De acordo com o Global Wind Report 2019 (GWEC, 2020), o modelo de leilão brasileiro, eficiente e competitivo, fez a capacidade instalada de energia eólica crescer de 0,6 GW para 15,4 GW nos últimos dez anos, fazendo o Brasil ocupar a sétima posição mundial em capacidade de energia eólica onshore instalada.
Segundo a ANEEL (2020), a fonte eólica corresponde a $8,94 \%$ da matriz elétrica brasileira em operação e apresenta índices de expansão significativos entre os empreendimentos de geração de energia elétrica outorgados em implantação, representando 33,04\% dos empreendimentos em construção e $27,82 \%$ daqueles cujas construções ainda não se iniciaram.

Devido aos avanços tecnológicos das turbinas eólicas, houve uma expansão da capacidade de geração de energia eólica. Isto ocasionou um aumento do diâmetro do rotor (RD),

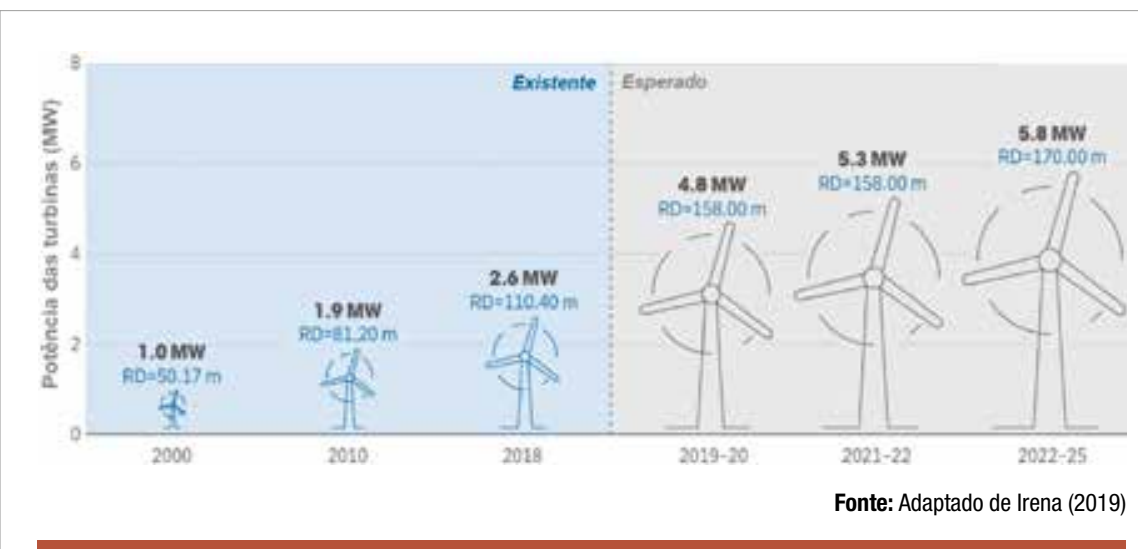

Figura 1

Evolução temporal das dimensões e da potência das turbinas eólicas 
que corresponde ao diâmetro medido entre as pás, e da altura das torres eólicas (IRENA, 2019), permitindo o contato das pás eólicas com ventos mais constantes e velozes, elevando a captação de energia, o fator de capacidade (percentual de aproveitamento) e, assim, a confiabilidade do sistema. Além disso, torres de maior altura são necessárias para garantir uma distância segura entre pás mais longas e o solo (LANTZ et al., 2019). Atualmente, as maiores torres eólicas no Brasil são de cerca de $120 \mathrm{~m}$ de altura, contudo já existem projetos com torres de 140 m. A Figura 1 apresenta uma evolução temporal das dimensões e das capacidades de geração das turbinas eólicas.

As torres eólicas podem ser formadas de segmentos feitos de aço ou concreto. As torres de segmento de concreto são mais viáveis para alturas superiores a 100 metros, uma vez que, quanto maior a altura, maiores e mais pesados serão os segmentos, dificul-

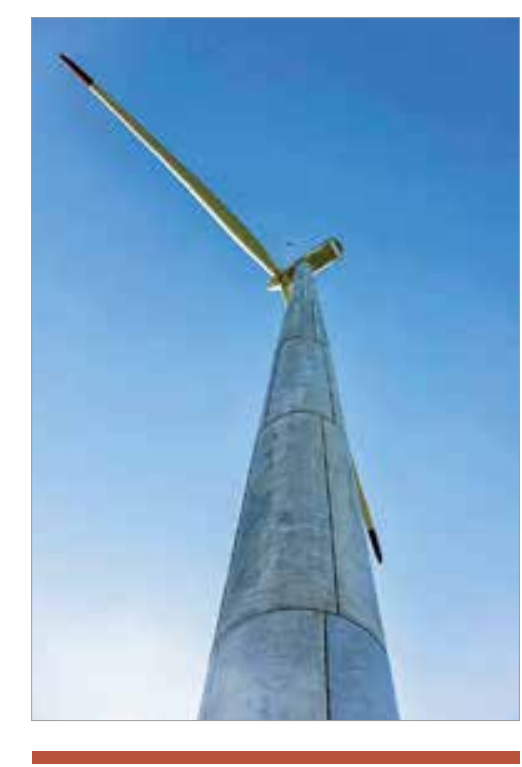

Figura 2

Torre eólica composta por segmentos de concreto pré-fabricado grauteados in loco tando, assim, o uso e o transporte de peças de aço. Geralmente, as alturas das torres de aço variam entre 65 e 80 metros (SANTOS, 2013). Os segmentos de concreto são pré-fabricados e grauteados para formar a torre, conforme ilustrado na foto apresentada na Figura 2.

Uma das propriedades mais relevantes do concreto dos segmentos da torre eólica é o módulo de elasticidade tangente inicial $\left(E_{c i}=\sigma / \varepsilon\right)$. $O E_{c i}$ é a propriedade mecânica que relaciona linearmente tensão $(\sigma)$ e deformação (ع) em materiais elásticos lineares, indicando a rigidez do concreto. É fundamental conhecer esse parâmetro para realizar análises estruturais (i.e. cálculo de tensões e deformações) e para fazer um correto dimensionamento da torre. Além disso, faz-se necessário controlar essa propriedade na fabricação dos segmentos da torre, para evitar danos estruturais, caso o módulo seja inferior ou superior ao preconizado em projeto. O valor do módulo de elasticidade costuma ser correlacionado ao valor da resistência à compressão do concreto (ANBT NBR 6118:2014), principalmente para fins de projeto, ou pode ser obtido por meio de ensaios laboratoriais realizados de acordo com o método descrito na ABNT NBR 8522:2017. Porém, vários fatores podem afetar o módulo de elasticidade do concreto, como o tipo e a dimensão máxima característica do agregado graúdo utilizado no traço, o empacotamento entre agregados graúdos e miúdos, dentre outros fatores (MEHTA \& MONTEIRO, 2014). Desse modo, é importante monitorar o módulo de elasticidade do concreto produzido para os segmentos eólicos, visto que grandes desvios com relação à consideração de projeto podem trazer comportamento inesperado du- rante o uso das torres eólicas, como vibrações excessivas, surgimento de fissuras e grandes deslocamentos.

As torres são sustentadas em fundações de grandes volumes de concreto armado, da ordem de centenas de metros cúbicos (Figura 3). Devido às suas dimensões, há um grande volume e uma área superficial relativamente pequena para troca de calor (gerado pelas reações de hidratação) com o ambiente para proporcionar o resfriamento do concreto; sendo assim, é necessário controlar a elevação de temperatura nessas estruturas.

A elevação de temperatura pode provocar o surgimento de fissuras por causa do acoplamento entre o fenômeno térmico (dilatação-contração dos materiais com variação de temperatura decorrida do calor gerado) e o mecânico (impedimento total ou parcial de movimentação do material no estado endurecido, por exemplo, pela ação de um gradiente de temperatura). As fissuras ocorrem quando as tensões de tração, de origem térmica, superam a resistência à tração do concreto (WU et al.2011). Outra manifestação patológica que pode surgir por consequência do aumento de temperatura é a decorrente da formação de etringita tardia (também conhecida como delayed et-

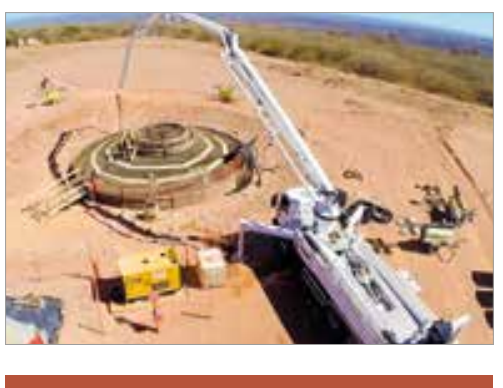

Figura 3

Concretagem de uma fundação de torre eólica 


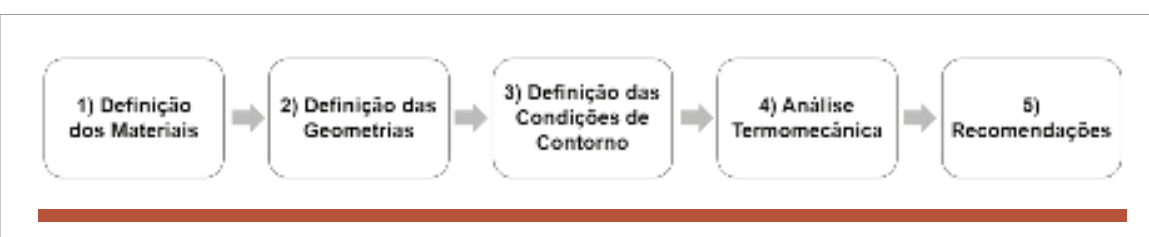

Figura 4

Etapas para a realização das simulações

tringite formation - DEF). Esse defeito pode ocorrer quando a temperatura do concreto é superior a $65^{\circ} \mathrm{C}$ durante as reações de hidratação, impedindo a formação de etringita ainda no estado fresco (em que ela é benigna), de maneira que a etringita acaba por se formar com o concreto já no estado endurecido. Por ser um fenômeno expansivo (LAROSCHE, 2009), a etringita formada posteriormente provoca o aumento de tensões internas no concreto, podendo rompê-lo ao exceder a capacidade resistente do material.

É possível fazer previsões e avaliações da temperatura interna de grandes volumes de concreto por meio da solução das equações do calor associadas ao problema (envolvendo o calor de hidratação do cimento como fonte e propagando-o por condução/convecção através do volume do material e de sua superfície). Softwares comerciais de elementos finitos podem ser utilizados. Pode-se estimar a evolução das temperaturas distribuídas no concreto com o tempo, as temperaturas máximas e determinar os pontos considerados críticos para o surgimento das fissuras de origem térmica. O monitoramento da temperatura, ao longo do tempo, em alguns pontos da estrutura, em conjunto com as previsões de modelo, permite avaliar o risco de fissuração térmica.

Este trabalho aborda dois temas importantes relacionados às torres eólicas: o módulo de elasticidade do concreto dos segmentos das torres e o estudo termomecânico necessário à realização das concretagens dos blocos de fundação, incluindo o posterior monitoramento das temperaturas do concreto desses blocos. Assim, este artigo apresenta um procedimento para estudo termomecânico de blocos de fundações, mostrando possíveis medidas para evitar elevações térmicas prejudiciais ao concreto. Apresenta ainda um estudo estatístico dos resultados dos ensaios de resistência à compressão e de módulo de elasticidade de concretos de segmentos produzidos com diferentes agregados. Os resultados aqui apresentados são provenientes dos estudos do Grupo de Pesquisa de Materiais de Construção e Estruturas (GPMATE) e do Grupo de Pesquisa em

Reologia (ReoM), ambos da Universidade Federal do Ceará (UFC), e foram desenvolvidos no Laboratório de Materiais de Construção Civil (LMCC) da UFC.

\section{ESTUDO TERMOMECÂNICO DE BLOCOS DE FUNDAÇÃO DE AEROGERADORES}

Para a realização de estudos termomecânicos de blocos de fundação, executam-se simulações em softwares comerciais de elementos finitos muito utilizados tanto no meio acadêmico quanto no meio profissional, como o b4cast, Comsol, Abaqus, Diana, entre outros. Tais softwares utilizam o método de elementos finitos para a realização do cálculo das temperaturas e das tensões de tração e compressão do concreto no interior dos blocos de fundação, em função do tempo.

Para a solução de problemas termomecânicos associados ao aquecimento do concreto, necessita-se de parâmetros do cimento, como a energia de ativação e a taxa de calor liberado durante a hidratação do cimento, de parâmetros do concreto, como o consumo de cimento no traço, a capacidade térmica, a massa específica, a condutividade térmica, o calor específico, o coeficiente de expansão térmica, o módulo de elasticidade, o coeficiente de Poisson, as resistências à tração e à compressão ao longo da idade, a temperatura inicial, entre outros. Esses parâmetros devem ser determinados por meio de ensaios ou estimados por meio de bibliografia especializada. Dados das condições de contorno da estrutura também devem ser inseridos, como a umidade relativa, a temperatura ambiente do local, a velocidade do vento, o tipo e tempo de utilização de fôrmas, as características do solo em contato com a estrutura,

Coeficiente de expansão térmica $1,15 \times 10^{-5}$

Fonte: Gonçalves (2018)

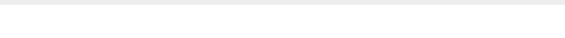

Tabela 1 - Parâmetros térmicos assumidos para o concreto estudado neste artigo 
dentre outros, conforme será melhor explicitado à frente.

As principais etapas para a execução das simulações estão especificadas na Figura 4. Neste artigo, para cada uma das etapas, será dado um exemplo de aplicação do procedimento de simulação para um bloco de fundação de concreto de uma torre eólica, utilizando-se o software b4cast.

\section{I Definição dos materiais}

Para as simulações, é fundamental ter a correta caracterização dos materiais constituintes do concreto e a caracterização realista das propriedades do próprio concreto. Uma maneira de medir a taxa de calor liberado durante a hidratação do cimento é por meio da calorimetria isotérmica. Além disso, existem normas brasileiras que estabelecem ensaios para encontrar a maioria dos parâmetros citados anteriormente, como a NBR 12820:2012 para condutividade térmica, a NBR 12817:2012 para o calor específico, a NBR 8522:2017 para o módulo de elasticidade, a NBR 5739:2018 para a resistência à compressão e a NBR 9778:2005 para a massa específica.

Na Tabela 1 são apresentadas as características térmicas do concreto, extraídas da bibliografia, utilizadas nas simulações apresentadas neste artigo. $\mathrm{Na}$ Figura 5, apresenta-se a evolução das resistências à compressão e à tração do concreto de $\mathrm{f}_{\mathrm{ck}}=30 \mathrm{MPa}$ utilizado no bloco de fundação da torre eólica, cuja simulação termomecânica é objeto deste artigo. Na Figura 6, apresenta-se os valores da elevação do módulo de elasticidade do concreto utilizado na simulação realizada, os quais foram obtidos de acordo com o método descrito pela ABNT NBR 8522:2017.

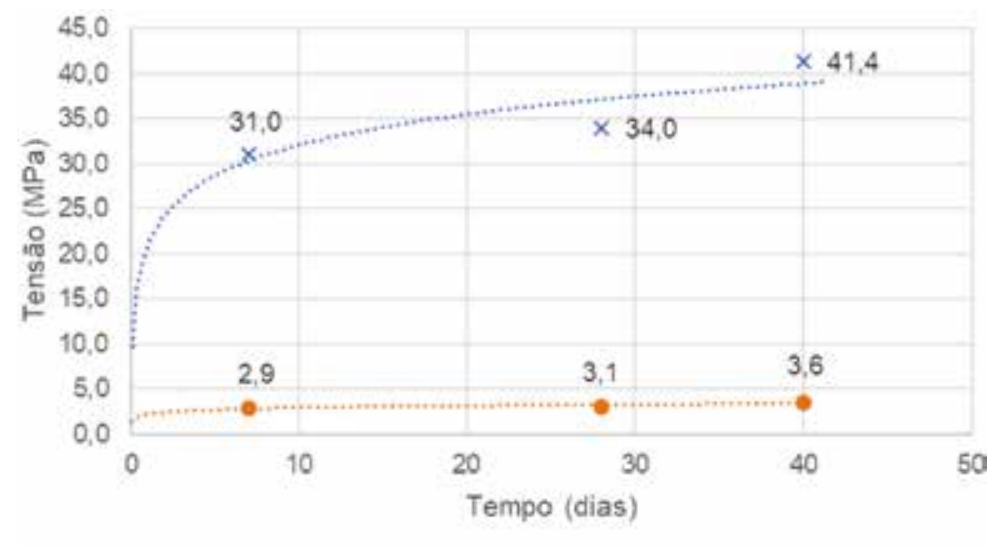

$\times$ Resistência à compressāo (MPa) - Resistência à traçăo (MPa)

Figura 5

Evolução das resistências à compressão e à tração do concreto de $30 \mathrm{MPa}$
Para evitar elevações térmicas prejudiciais ao concreto, recomenda-se utilizar cimentos classificados como de baixo calor de hidratação, os quais, de acordo com a NBR 16697:2018, possuem calor total gerado menor que $270 \mathrm{~J} / \mathrm{g}$ em $41 \mathrm{~h}$ de ensaio. Na Tabela 2, são apresentados dados de calor de hidratação para vários tipos de cimento fabricados no Brasil.

É importante destacar que se deve ter cautela ao utilizar valores desses parâmetros provenientes da literatura, uma vez que eles podem não representar os materiais utilizados na construção das estruturas, distanciando, dessa forma, as simulações da realidade (COUTO, 2018).

\subsection{Definição das geometrias}

A outra etapa necessária é a definição das geometrias. De acordo com o projeto da estrutura estudada

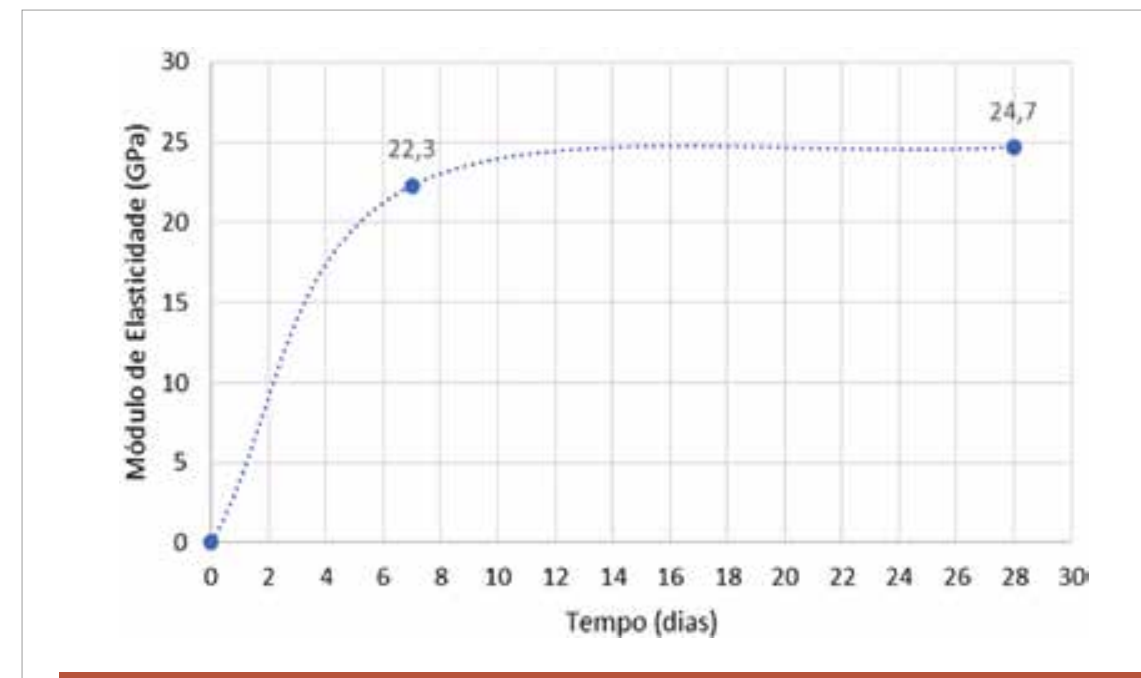

Figura 6

Evolução do módulo de elasticidade do concreto de $30 \mathrm{MPa}$ 
Tabela 2 - Dados de calor de hidratação de cimentos

\begin{tabular}{|c|c|c|c|c|}
\hline \multirow{2}{*}{$\begin{array}{l}\text { Tempo } \\
\text { (horas) }\end{array}$} & \multicolumn{4}{|c|}{$\begin{array}{l}\text { Calor de hidratação } \\
(\mathrm{J} / \mathrm{g})\end{array}$} \\
\hline & CP II-E 32 RS & $\begin{array}{c}\text { CP IV } 32 \\
\text { com pozolana } \\
\text { natural }\end{array}$ & CP III 40 & $\begin{array}{l}\text { CP IV } 32 \text { com } \\
\text { cinza volante }\end{array}$ \\
\hline 12 & 115 & 105 & 78 & 62 \\
\hline 24 & 192 & 182 & 164 & 149 \\
\hline 41 & 236 & 220 & 202 & 194 \\
\hline 72 & 261 & 240 & 224 & 212 \\
\hline 120 & 280 & 249 & 240 & 226 \\
\hline 168 & 291 & 257 & 250 & 234 \\
\hline
\end{tabular}

Fonte: Cabral (2017)

(Figura 7a), deve-se criar seu volume no software (Figura 7b).

\subsection{Definição das condições de contorno}

As condições de contorno que serão aplicadas às geometrias definidas anteriormente podem ter grande influência sobre os resultados da simulação. Dessa maneira, diferentes estratégias podem ser preconizadas, devendo balancear a intenção de buscar a mais precisa representação da realidade possível, com suficiente simplicidade.

Para a definição das temperaturas de convecção, deve-se considerar a temperatura ambiente média do local onde a estrutura será construída. A transferência de calor por convecção ocorre entre um fluido em movimento e uma superfície, como a face de fôrmas e o vento (INCROPERA; DEWITT; BERGMAN; LAVINE, 2008). Além disso, se, nas laterais da geometria, existir algum elemento como fôrmas ou material isolante, seus coeficientes de condutividade térmica, suas espessuras e seus tempos de contato devem ser considerados. As características do solo em contato com o bloco devem entrar na caracterização do contorno, como calor específico, condutividade térmica, módulo de deformação e dimensões. Por fim, deve-se aplicar a velocidade do vento às faces da geometria expostas a ele.

Na Figura 7, tem-se a exemplificação de uma aplicação das condições de contorno, onde pode-se verificar que, nas laterais dos cilindros inferior $e$ superior da fundação, tem-se chapa de aço como fôrma lateral e, nas demais áreas, tem-se $\mathrm{O}$ ar. $\mathrm{Na}$ face inferior da fundação, que não aparece na Figura 8, colocou-se o solo como condição de contorno. A partir dessa definição, propriedades térmicas dos materiais em contato com o concreto ficam definidas a partir da biblioteca do software.

\subsection{Análise termomecânica}

Para as análises, deve-se definir o modo de construção da estrutura, escolhendo se a concretagem será realizada em uma única etapa ou se será dividida em camadas, por exemplo. Além disso, é preciso definir a malha de elementos finitos utilizada. A Figura 9 apresenta a malha utilizada, formada por elementos tetraédricos. A distância entre os nós deve ser estabelecida de maneira que haja convergência dos resultados (pequena variação na simulação quando do aumento da densidade

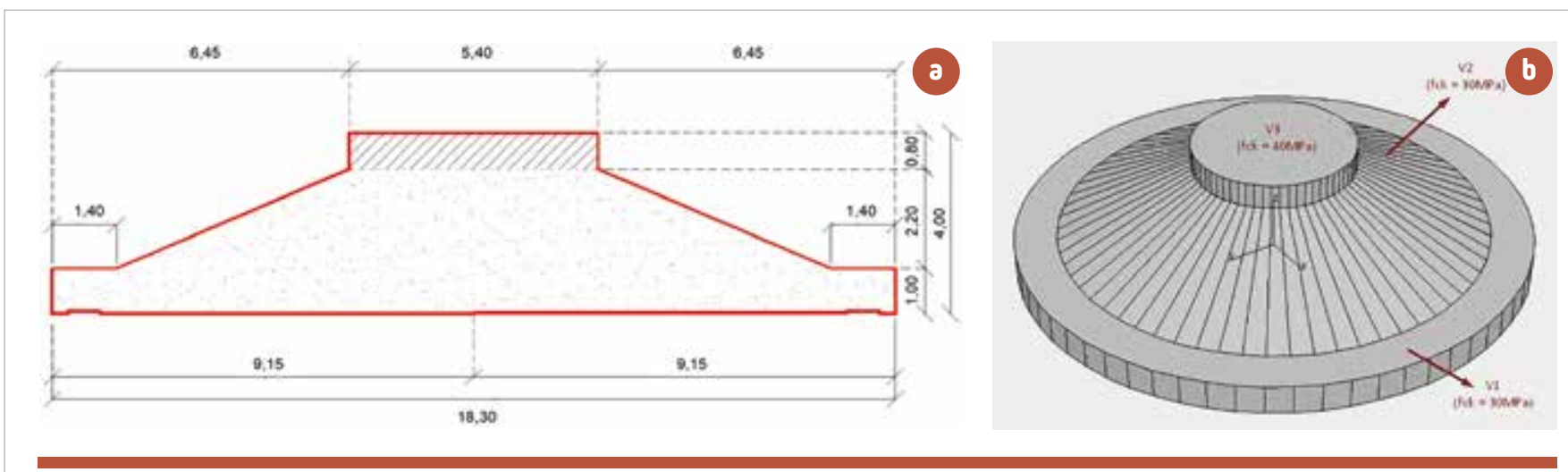

Figura 7

a) exemplo de um corte de uma fundação de torre eólica; b) volume criado em software de elementos finitos 


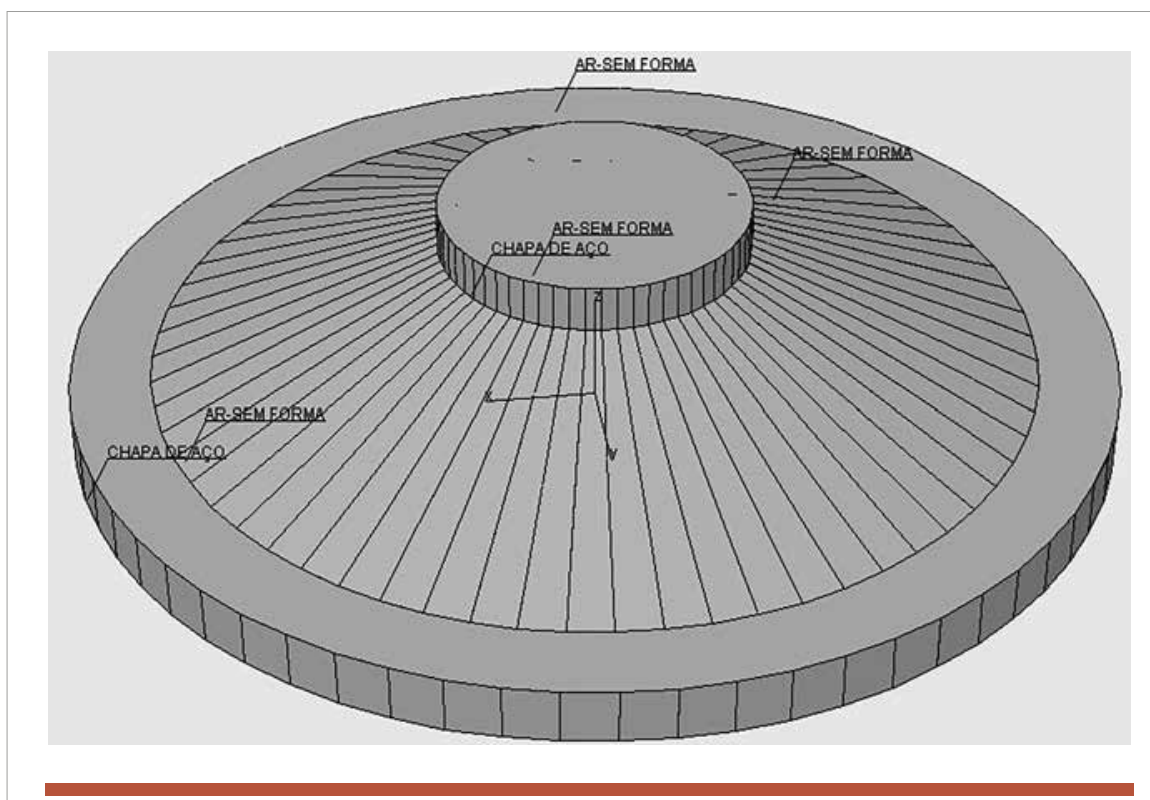

Figura 8

Exemplificação de condições de contorno do item fôrmas

da malha). Em estruturas axissimétricas, pode-se simular apenas uma parte da estrutura, reduzindo o esforço computacional, desde que consideradas condições de contorno adequadas.

Apesar de não haver nenhuma norma brasileira que estabeleça um limite máximo para a temperatura do concreto durante a hidratação, pode-se encontrar algumas considerações dessa temperatura na literatura, como $65{ }^{\circ} \mathrm{C}$ (MEHTA \& MONTEIRO, 2014) e $70{ }^{\circ} \mathrm{C}$ (TAYLOR; FAMY; SCRIVENER, 2001). A temperatura limite mais adotada no Brasil é $65^{\circ} \mathrm{C}$. Para as tensões de tração, uma das condições para que não haja fissuras é que as tensões de tração máximas solicitantes, oriundas da retração térmica do concreto, não sejam superiores às tensões de tração resistentes, ao longo de todo o tempo de simulação. Usualmente, os softwares apresentam os valores de tensão de tração solicitante e resistente em qualquer ponto da geometria da fundação.

A análise de linhas isotermas, que unem pontos com iguais valores de temperatura, é outro elemento de grande importância para interpretar os resultados das simulações térmicas. Por meio delas, é possível visualizar os valores de temperatura no interior da estrutura. A Figura 10 exemplifica linhas isotermas em um corte no centro de um bloco de fundação, no instante em
Figura 10

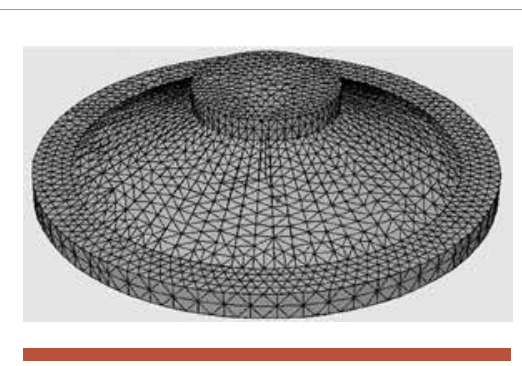

Figura 9

Malha definida em software de elementos finitos com distância de $60 \mathrm{~cm}$ entre os nós

que alcançou suas temperaturas máximas, chegando a atingir $64^{\circ} \mathrm{C}$.

Adicionalmente, é importante que sejam escolhidos pontos no interior da estrutura para realizar o acompanhamento, em campo, das temperaturas e tensões de tração durante um certo período, usualmente até 15 dias após a concretagem. Na Figura 11, tem-se um exemplo de pontos escolhidos para monitoramento de uma estrutura (pontos A a H), enquanto, na Figura 12, apresenta-se a elevação térmica em cada ponto ao longo do tempo. Geralmente os pontos são escolhidos pela

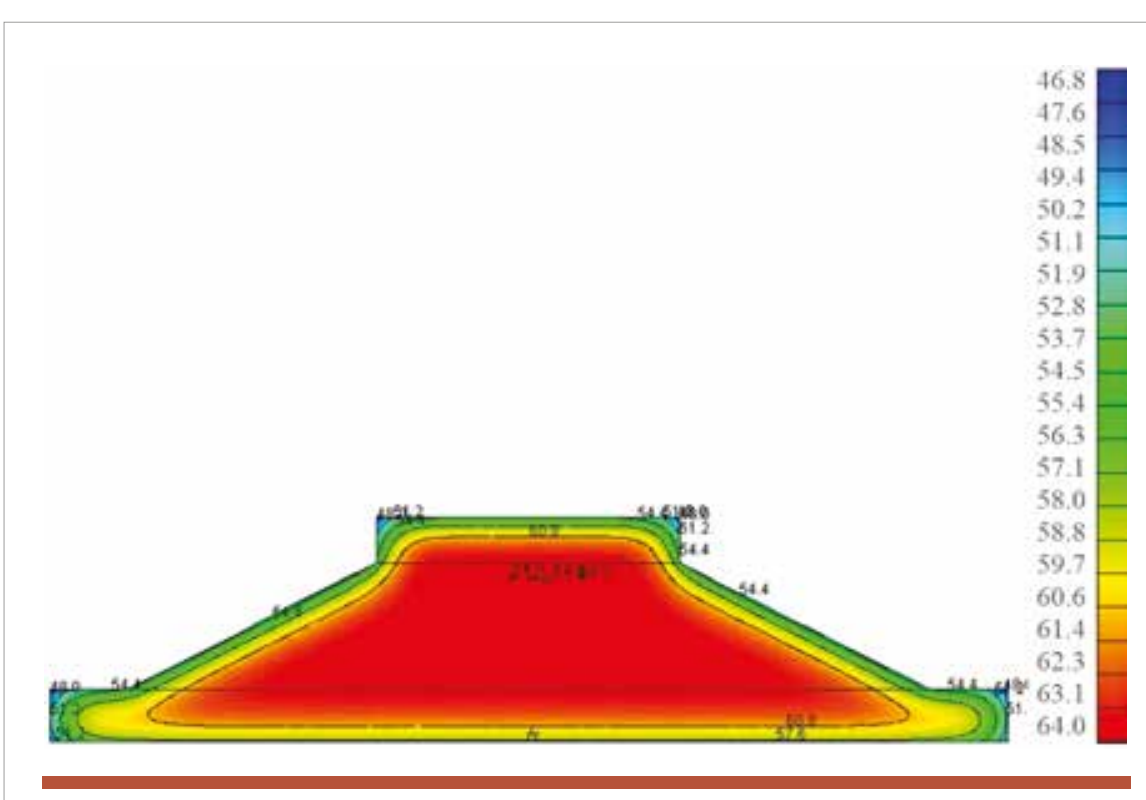

Isotermas no centro do bloco de fundação com as temperaturas máximas obtidas 


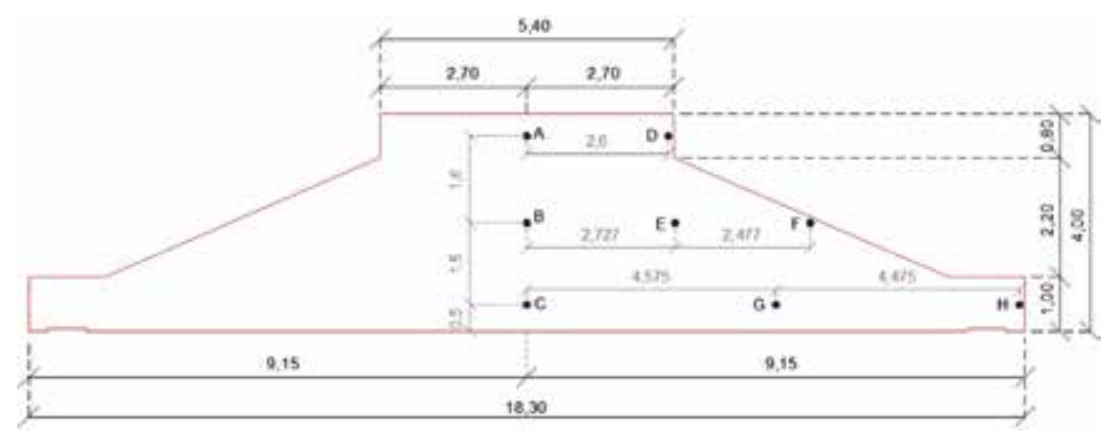

Figura 11

Localização de pontos a terem suas temperaturas e tensões acompanhadas

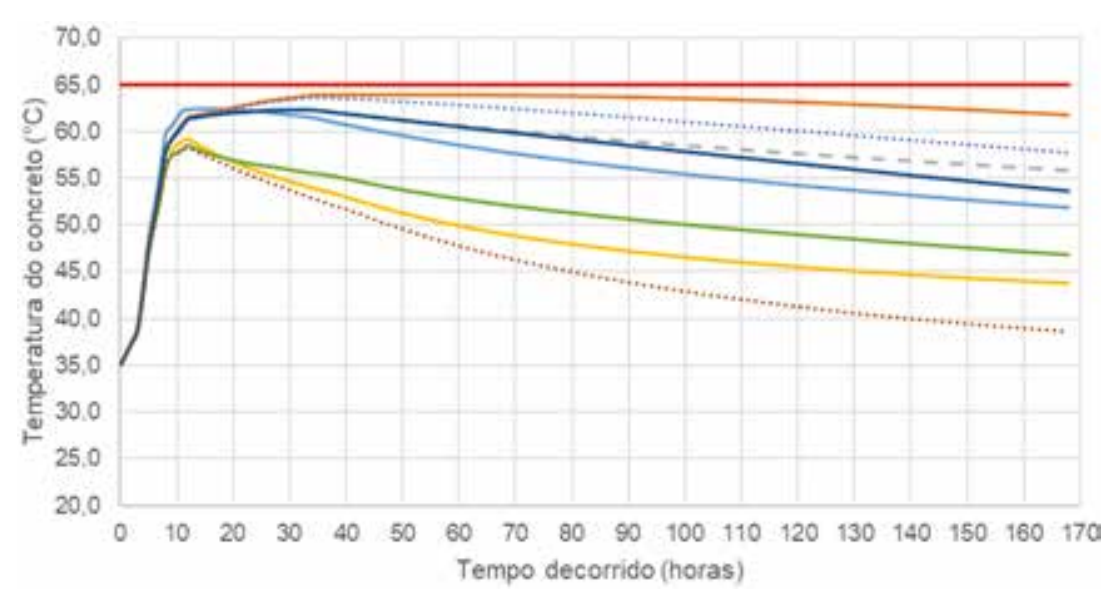

Figura 12

Temperatura ao longo do tempo em cada ponto selecionado da fundação (conforme Figura 11)

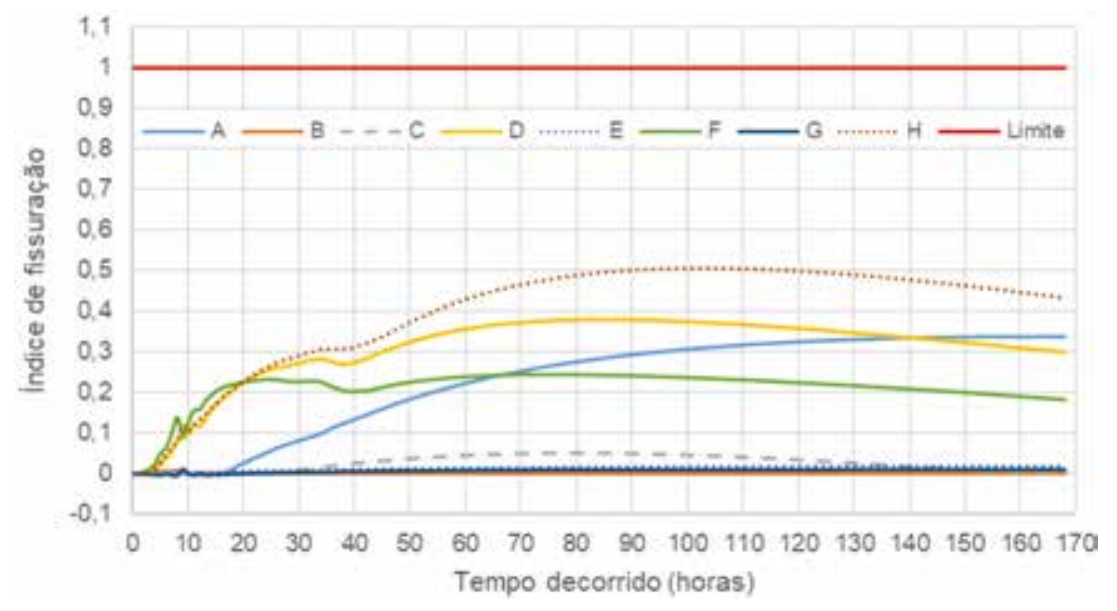

Figura 13

Evolução do índice de fissuração nos pontos $\mathrm{A}$ a $\mathrm{H}$ do bloco de fundação ao longo do tempo tendência de atingirem as temperaturas máximas (pontos $B, E, C$ e $G$ do exemplo) da estrutura (pontos distantes das superfícies de troca de calor com o ambiente) e pela maior possibilidade de alcançarem as tensões máximas solicitantes de tração (pontos A, D, F e H do exemplo) da estrutura (pontos com maior gradiente de temperatura).

Para avaliar o risco de fissuração, alguns softwares, como o b4cast, definem um indicador denominado de índice de fissuração, o qual é a razão entre a tensão de tração solicitante $e$ a tensão de tração resistente do concreto em um dado momento. Se esse índice for maior que 1 significa que a tensão de tração solicitante prevista é maior que a resistente naquele ponto $e$ que a peça irá fissurar. Se esse índice for menor que 1, a peça não deve fissurar naquele ponto. A Figura 13 mostra o acompanhamento desse índice para cada ponto da fundação exemplificada neste artigo, verificando-se, por meio dele, que a estrutura não corre o risco de fissurar, uma vez que o índice de fissuração apresentado até 7 dias de idade não supera o valor unitário.

\subsection{Recomendações $\in \mathrm{m}$ função das análises termomecânicas}

As análises termomecânicas para aplicação no estudo das fundações de concreto determinam duas coisas: (i) a temperatura máxima de lançamento do concreto de forma que as temperaturas máximas previstas no concreto não ultrapassem o valor máximo permitido, neste caso sendo considerado $65^{\circ} \mathrm{C}$; e (ii) zonas com tendência de fissuração devido à retração térmica. De posse da temperatura máxima de lançamento do concreto, deve-se buscar mecanismos para se atingir tal temperatura, 


\section{Tabela 3 - Balanço térmico de um concreto de $30 \mathrm{MPa}$}

\begin{tabular}{|c|c|c|c|c|c|c|}
\hline Materiais & $\begin{array}{c}\text { Quantidade para } \\
1 \mathrm{~m}^{3} \mathrm{de} \text { concreto } \\
(\mathrm{kg})\end{array}$ & $\begin{array}{l}\text { Calor específico } \\
\left(\text { kcal/kg }{ }^{\circ} \mathrm{C}\right)\end{array}$ & $\begin{array}{l}\text { Calor latente } \\
\text { (kcal/kg) }\end{array}$ & $\begin{array}{l}\text { Temperatura } \\
\text { inicial } \\
\left({ }^{\circ} \mathrm{C}\right)\end{array}$ & $\begin{array}{c}\text { Q2 }=\mathrm{m}^{*} \mathrm{ce}^{*} \text { (Ti-Tif) } \\
\text { (kcal) }\end{array}$ & $\begin{array}{l}Q 1=\mathrm{mg}^{*} \mathrm{C} \\
(\mathrm{kcall})\end{array}$ \\
\hline Cimento & 310,0 & 0,20 & - & 70 & 2666,0 & - \\
\hline Areia & 757,0 & 0,19 & - & 42 & 2157,5 & - \\
\hline Brita 2,5 & 213,0 & 0,20 & - & 42 & 639,0 & - \\
\hline Brita 19 & 853,0 & 0,20 & - & 42 & 2559,0 & - \\
\hline Água & 90,9 & 1,00 & - & 42 & 1362,9 & - \\
\hline Gelo & 88,1 & - & $-80,0$ & - & - & $-7051,1$ \\
\hline Água do gelo & 88,1 & 1,00 & - & 0 & $-2379,8$ & - \\
\hline \multirow[t]{2}{*}{ Aditivo } & 3,1 & 1,00 & - & 42 & 46,5 & - \\
\hline & & & & SOMA (kcal) & & \\
\hline \multicolumn{2}{|c|}{ Temperatura de lançamento } & 27 & & & & \\
\hline
\end{tabular}

tais como: o resfriamento da água de amassamento, usualmente para valores entre $1^{\circ} \mathrm{C}$ e $5^{\circ} \mathrm{C}$; a troca de água de amassamento por gelo; o resfriamento dos agregados; o resfriamento da massa do concreto por meio de dutos inseridos nela onde se passaria água ou gás frio; dentre outros. No caso da estrutura exemplificada neste artigo, utilizou-se a substituição de água do traço do concreto por gelo, colocando- o diretamente no caminhão betoneira.

A Tabela 3 apresenta, de forma

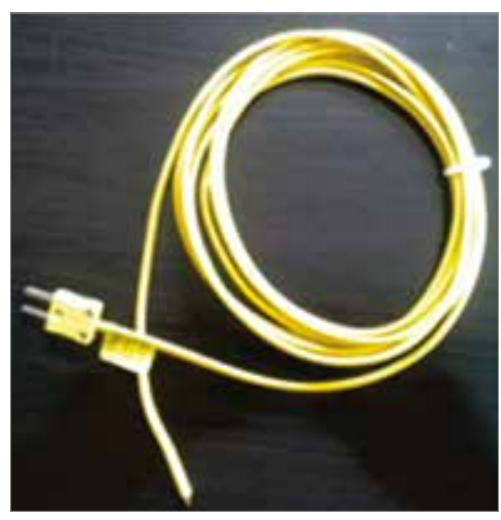

Figura 14

Termopar para monitoramento da temperatura dentro do bloco de fundação ilustrativa, o balanço térmico do traço de concreto, de forma a se determinar a quantidade de gelo necessária na mistura, de forma que a temperatura de lançamento do concreto seja de $27^{\circ} \mathrm{C}$. Isso se calcula considerando a quantidade de calor retirada do concreto pela ação do derretimento do gelo $\left(Q_{1}=m_{g}{ }^{*} C_{L}\right)$, que resfria o concreto $\left(Q_{2}=m^{*} C_{e}^{*}\left(T_{i}-T_{f}\right)\right)$. Em que:

$\mathrm{Q}_{1}=$ Quantidade de calor latente (kcal); $\mathrm{Q}_{2}=$ Quantidade de calor sensível (kcal); $\mathrm{m}_{\mathrm{g}}=$ Massa de gelo $(\mathrm{kg})$;

$\mathrm{m}=$ Massa dos demais materiais $(\mathrm{kg})$;

$\mathrm{C}_{\mathrm{L}}=$ Calor latente $(\mathrm{kcal} / \mathrm{kg})$;

$\mathrm{C}_{\mathrm{e}}=$ Calor específico ( $\left.\mathrm{kcal} / \mathrm{kg}^{\circ} \mathrm{C}\right)$;

$\mathrm{T}_{\mathrm{i}}=$ Temperatura inicial $\left({ }^{\circ} \mathrm{C}\right)$;

$\mathrm{T}_{\mathrm{f}}=$ Temperatura de lançamento $\left({ }^{\circ} \mathrm{C}\right)$.

Além do estabelecimento da temperatura de lançamento do concreto e de sua conferência, faz-se necessário medir, in loco, as temperaturas nas regiões críticas dos blocos de fundação. Recomenda-se a instalação de sensores de temperatura, como termopares (Figura 14), fixados nos pontos críticos identificados durante as simulações, conforme montagem representada na Figura 15.

A aquisição dos dados de temperatura deve ser realizada por meio de registrador eletrônico de temperatura, o qual pode ser manual ou automático. É desejável que o equipamento possua memória para registro eletrônico, com interface para posterior descarregamento dos dados em computador. Recomenda-se, por fim, que a aquisição das temperaturas seja horária até as 50 horas após a concretagem e, após isso, de 3 em 3 horas, até que a temperatura se estabilize. Isso permitirá confrontar os resultados do modelo com a realidade e gerar informação

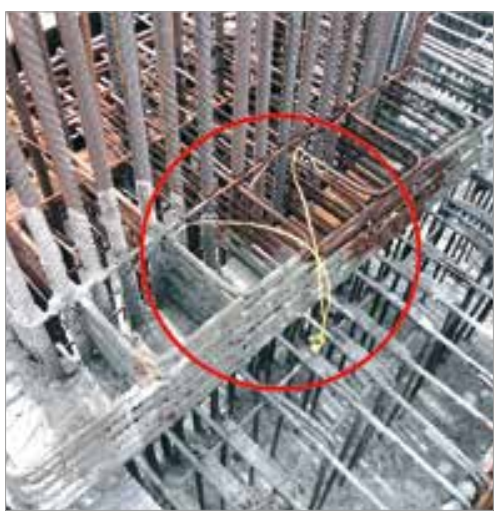

Figura 15

Termopares instalados nas armaduras antes da concretagem de uma estrutura de fundação 
para tomada de decisão rápida, caso necessária alguma ação, como, por exemplo, aumentar a quantidade de gelo no traço ou reduzir a temperatura dos agregados.

\section{ESTUDO DO MÓDULO DE ELASTICIDADE DO CONCRETO DOS SEGMENTOS DA TORRE EÓLICA}

Como já mencionado neste artigo, as torres eólicas de concreto são produzidas em segmentos e o concreto destes deve apresentar propriedades mecânicas e de durabilidade que assegurem uma vida útil adequada aos projetos. O módulo de elasticidade é uma das propriedades mais importantes do concreto desses segmentos, pois ditará a deformabilidade da estrutura.

Muitos dos projetos de torres eólicas instaladas no Brasil eram produzidos fora do país, com normativas eu-

\section{Tabela 4 - Resistência}

característica à compressão aos 28 dias e módulo de elasticidade utilizados em projetos conforme ABNT NBR 6118:2014

\begin{tabular}{|c|c|}
\hline $\begin{array}{c}\text { Resistência do } \\
\text { concreto }\left(f_{\mathrm{ok}}\right), \\
\mathrm{em} \mathrm{MPa}\end{array}$ & $\begin{array}{r}\text { Módulo de } \\
\text { elasticidade } \\
\text { estimado }\left(\mathrm{E}_{\mathrm{o}}\right), \\
\mathrm{em} \mathrm{GPa}\end{array}$ \\
\hline 20 & 21 \\
\hline 25 & 24 \\
\hline 30 & 27 \\
\hline 35 & 29 \\
\hline 40 & 32 \\
\hline 45 & 34 \\
\hline 50 & 37 \\
\hline 60 & 40 \\
\hline 70 & 42 \\
\hline 80 & 45 \\
\hline 90 & 47 \\
\hline
\end{tabular}

ropeias e americanas. De alguns anos para cá, alguns projetos passaram a ser calculados no Brasil, usualmente empregando o módulo de elasticidade conforme preconizado pela NBR 6118:2014. Segundo tal norma, o módulo tangente inicial do concreto $\left(E_{\mathrm{c}}\right)$ pode ser estimado, aos 28 dias, por meio das Equações 1 e 2.

$$
\begin{array}{l|l|}
\hline E_{c i}=\alpha_{E} \times 5600 \sqrt{f_{c k}} & 1 \\
\hline E_{c i}=21.5 \times 10^{3} \times \alpha_{E} \times\left(\frac{f_{c k}}{10}+1.25\right)^{1 / 3} & 2 \\
\hline
\end{array}
$$

A Equação 1 refere-se aos concretos com resistência característica $\left(f_{c k}\right)$ entre $20 \mathrm{MPa}$ e $50 \mathrm{MPa}$, e a Equação 2 para $f_{c k}$ de $55 \mathrm{MPa}$ até $90 \mathrm{MPa}$. O valor de $a_{E}$ é um parâmetro que depende da natureza do agregado graúdo utilizado no concreto. A ABNT NBR 6118:2014 sugere que $\mathrm{o} \mathrm{a}_{\mathrm{E}}$ para agregados de arenito, calcário, granito/gnaisse e basalto/ diabásico, seja 0,7, 0,9, 1,0 e 1,2, respectivamente. Enquanto isso, $\mathrm{f}_{\mathrm{ck}}$ assume o valor da resistência característica à compressão do concreto empregado no projeto.

A Tabela 4 apresenta os valores estimados do módulo de elasticidade do concreto em função de sua resistência característica à compressão, para agregado granítico, ou seja, para $a_{E}=1,0$. Convém ressaltar que, usualmente, as resistências características dos concretos dos segmentos de torre eólica são superiores a $50 \mathrm{MPa}$.

Estudos realizados no Ceará, estado com grande concentração de parques eólicos, por Oliveira (2019), mostraram que o valor de $a_{E}$ para os concretos produzidos com os agregados do estado, que são granito ou gnaisse, não é igual a 1. No referido estudo, foram avaliadas as resistências à compressão e o módulo de elasticidade de quatro concreteiras, avaliando-se concretos de $\mathrm{f}_{c k}$ iguais a $25 \mathrm{MPa}, 30 \mathrm{MPa}$ e 35 MPa. Como exemplo, tem-se o gráfico da Figura 16, no qual é possível verificar a correlação entre o módulo de elasticidade e a resistência à compressão para uma concreteira do estado do Ceará.

Como pode ser visto na Figura 16, para um determinado valor de resistência à compressão, o valor experimental do módulo de elasticidade encontrado é inferior ao valor teórico. Isto significa que $\mathrm{O} \mathrm{a}_{\mathrm{E}}$ dos concretos desta concreteira é inferior a 1,00. As equações que

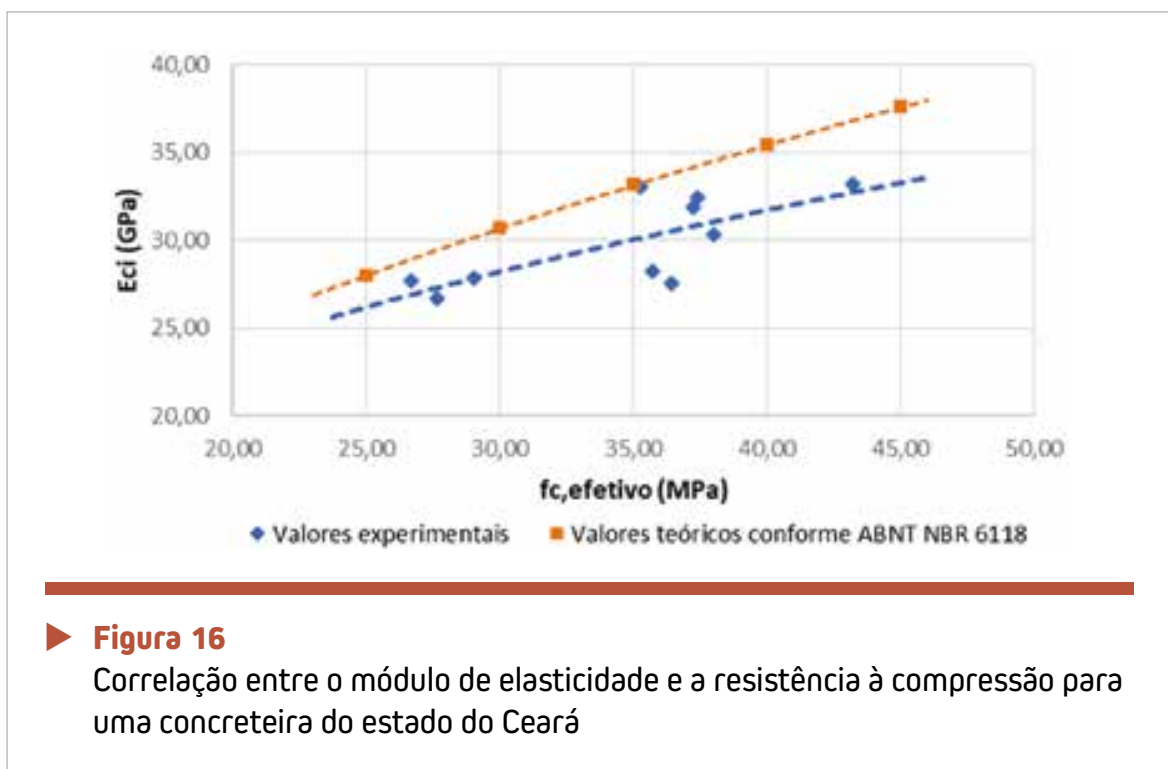




\section{Tabela 5 - Equações de correlação entre as resistências à compressão} e o módulo de elasticidade e os seus respectivos valores de $\alpha_{E}$

\begin{tabular}{ccc} 
Concreteira & Correlaçä̃o entre Eci e fc & $\alpha_{\mathrm{E}}$ \\
\hline A & $E_{\mathrm{ci}}=5,199 \mathrm{f}_{\mathrm{c}}^{0,5}$ & 0,928 \\
\hline B & $E_{\mathrm{ci}}=5,087 \mathrm{f}_{\mathrm{c}}^{0,5}$ & 0,908 \\
\hline C & $\mathrm{E}_{\mathrm{ci}}=3,727 \mathrm{f}_{\mathrm{c}}^{0,5}$ & 0,666 \\
\hline$D$ & $\mathrm{E}_{\mathrm{ci}}=4,933 \mathrm{f}_{\mathrm{c}}^{0,5}$ & 0,881 \\
\hline
\end{tabular}

regem a correlação entre as resistências à compressão, o módulo e seus respectivos $\alpha_{E}$ estão apresentados na Tabela 5.

Um outro estudo similar foi realizado pelo Grupo de Pesquisa em Materiais de Construção e Estruturas (GPMATE) da Universidade Federal do Ceará (UFC). Contudo, desta vez, mantiveram-se os traços de concreto e variaram-se os tipos de agregado graúdo. Foram avaliados dois agregados de composição mineralógica diferentes: um granito, proveniente do Ceará, e um basalto, proveniente do Piauí, com o intuito de investigar a influência destes agregados no módulo de elasticidade dos concretos desenvolvidos. Vale destacar que os agregados apresentavam a mesma distribuição granulométrica e que esse concreto era para uso em segmentos de torre eólica. $O f_{c k}$ do concreto era de 50 MPa e o módulo de elasticidade desejado era de $37 \mathrm{GPa}$.

Com os corpos de prova moldados, realizaram-se os ensaios para a determinação do módulo de elasticidade, de acordo com a ABNT NBR 8522:2017 aos 3, 7, 14 e 28 dias. A Figura 17 apresenta a evolução do módulo do concreto para cada tipo de agregado. A Figura 18 apresenta as linhas de tendência obtidas para a correlação.

Percebe-se, conforme Figuras 17 e 18, que os agregados de basalto propiciam maior módulo de elastici- dade ao concreto, aproximadamente $21 \%$ superiores ao com os agregados de granito. Conforme Figura 18, pode-se observar que, para uma resistência à compressão de $50 \mathrm{MPa}$, o módulo de elasticidade do concreto
Figura 17 agregados diferentes

Figura 18 produzido com a brita granítica cearense era de $28 \mathrm{GPa}$. Para o concreto de $50 \mathrm{MPa}$ com a brita basáltica, o módulo era $34 \mathrm{GPa}$.

Percebe-se também que, para se conseguir os desejáveis 37 GPa de módulo de elasticidade, o concreto com a brita basáltica deveria atingir $62 \mathrm{MPa}$ de resistência à compressão, enquanto que não foi possível atingir tal módulo com a brita granítica. Contudo, como mencionado, os agregados basálticos eram obtidos do Piauí, distantes cerca $600 \mathrm{~km}$ da fábrica de segmentos de concreto para as torres eólicas. Os custos de transporte inviabilizavam a obra.

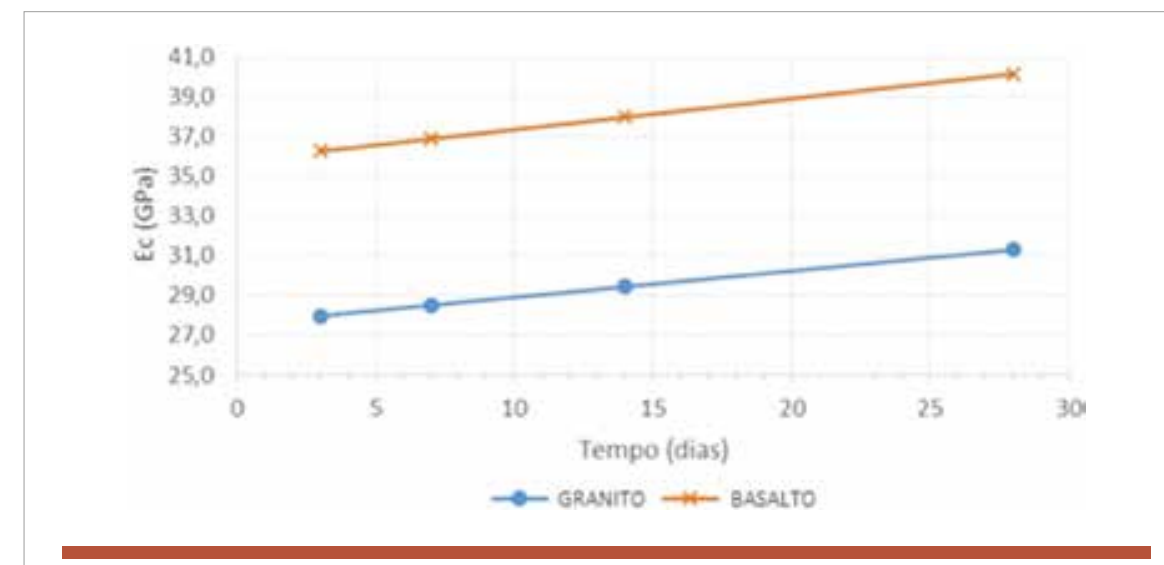

Evolução do módulo de elasticidade no tempo dos concretos produzidos com

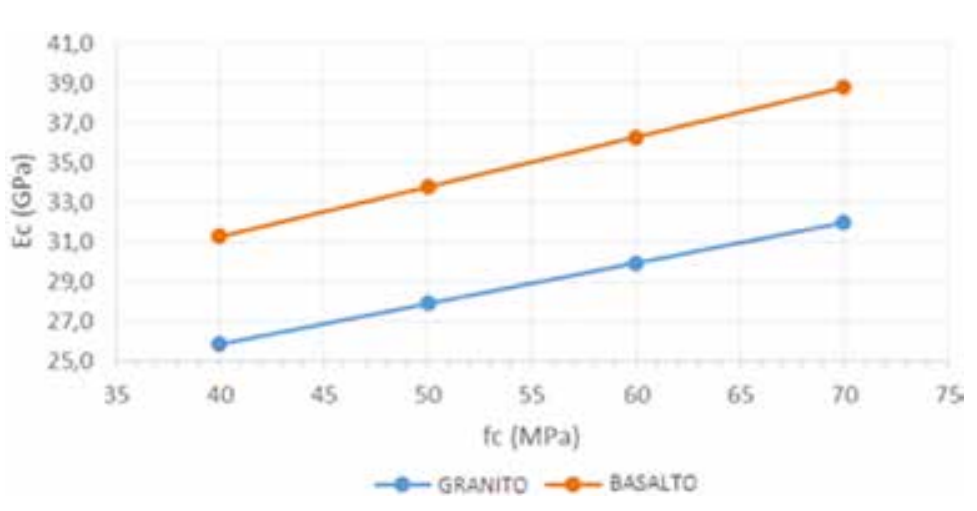

Relação entre a resistência à compressão e o módulo de elasticidade dos concretos produzidos com agregados diferentes 
Assim, considerando que, com os agregados locais, não era possível produzir um concreto com módulo de elasticidade de $37 \mathrm{GPa}$, inviabilizando tecnicamente a obra, e que o transporte dos agregados basálticos do Piauí inviabilizavam financeiramente a obra, restou a opção de mudar o projeto, adotando módulos de elasticidade mais factíveis de serem obtidos com os agregados locais.

\section{CONCLUSÃO}

Quanto à análise termomecânica, este artigo mostrou, discutindo os parâmetros intervenientes, o procedimento para a investigação tanto da evolução de temperatura quanto do índice de fissuração em fundações de concreto de torres eólicas por meio de um software comercial. Os resultados permitem estimar temperaturas máximas de lançamento dos concretos para evitar o surgimento de manifestações patológicas que prejudiquem o desempenho e durabilidade dessas estruturas. Recomenda-se a escolha de pontos de controle de temperaturas máximas (geralmente no centroide da estrutura e adjacências) e de tensões máximas (geralmente nas bordas) para que, com os resultados, seja possível encontrar os pontos mais críticos, nos quais devem ser instalados termopares para o monitoramento das fundações in loco.

Quanto ao comportamento mecânico do concreto, apresentou-se a importância da análise da influência do tipo de agregado graúdo no módulo de elasticidade do concreto dos segmentos de torres eólicas, com relevantes desvios observados em concretos com relação às estimativas a partir da resistência mecânica conforme normativa brasileira. Verificou-se que o tipo de rocha exerce grande influência na obtenção do módulo e que, portanto, deve ser um aspecto que deve ser levado em consideração na realização de projetos de torres eólicas.

Como alguns dos valores das propriedades térmicas e mecânicas do concreto são obtidos da literatura, faz-se necessário o uso de fatores de segurança, uma vez que os resultados das modelagens nunca refletem inteiramente a realidade e, portanto, dependendo dos dados de entrada no software, os resultados podem ser não verossímeis.

\section{DREFERÊNCIAS BIBLIOGRÁFICAS}

[01] ANEEL - AGÊNCIA NACIONAL DE ENERGIA ELÉTRICA. ANEEL libera a operação comercial de 2 mil MW até março de 2020. 2020. Disponível em: https://bit. Iy/2Jzyw1s. Acesso em: 27 maio 2020.

[02] B4CAST (2019). (Versão 6.15) [Software]. Allerød, Denmark: ConTech Analysis ApS.

[03] CABRAL, A. E. B. Avaliação de cimento pozolânico produzido com fly ash como proteção para ambientes agressivos. Palestra ministrada no Inovaconstruir 2017. Sinduscon/CE, 2017, Fortaleza.

[04] COUTO, D. A. Considerações sobre a temperatura em elementos de fundação em concreto de grandes dimensões. 2018. 145 f. Dissertação (Mestrado) - Curso de Faculdade de Engenharia Civil, Arquitetura e Urbanismo, Universidade Estadual de Campinas, Campinas, 2018.

[05] GONÇALVES, L. F. Avaliação de propriedades térmicas do concreto com cinza volante em fundação de aerogeradores. 2018. 85 f. Dissertação (Mestrado) - Curso de Mestrado em Engenharia Civil: Construção Civil, Departamento de Engenharia Estrutural e Construção Civil, Universidade Federal do Ceará, Fortaleza, 2018.

[06] GWEC - Global Wind Energy Council. Global Wind Report2019. Bruxelas, 2020.

[07] INCROPERA, F. P.; DeWITT, D. P.; BERGMAN, T. L.; LAVINE, A. S. Fundamentos da transferência de calor e de massa. $6^{a}$ ed. Tradução e Revisão de Eduardo M. Queiroz e Fernando Luiz P. Pessoa. Ed. LTC. Rio de Janeiro, 2008.

[08] IRENA - International Renewable Energy Agency. Future of wind: Deployment, investment, technology, grid integration and socio-economic aspects. A Global Energy Transformation paper. Abu Dhabi, 2019. (978-92-9260-155-3).

[09] LANTZ, E.; ROBERTS, O.; NUNEMAKER, J.; DEMEO, E.; DYKES, K.; SCOTT, G. Increasing Wind Turbine Tower Heights: Opportunities and Challenges. Golden, CO: National Renewable Energy Laboratory. NREL/TP-5000-73629. 2019. Disponivel em: https://www.nrel.gov/docs/fy19osti/73629.pdf.. Acesso em: 27 maio 2020.

[10] LAROSCHE, C.J. Types and causes of cracking in concrete structures. Failure, Distress And Repair Of Concrete Structures, [s.I.], p. 57-83, 2009. Elsevier. http://dx.doi.org/10.1533/9781845697037.1.57.

[11] MEHTA, P. K.; MONTEIRO, P. J. M. Concreto: Estrutura, Propriedades e Materiais. 2 ed. São Paulo: IBRACON, 2014.

[12] OLIVEIRA, J. L. S. Estudo comparativo entre o módulo de elasticidade real e o teórico de concretos de Fortaleza. Projeto de graduação. Curso de Engenharia Civil. Universidade Federal do Ceará. Fortaleza, 2019.

[13] SANTOS, A. Logística favorece concreto nos parques eólicos: possibilidade de construir peças pré-fabricadas in loco permite que material seja competitivo diante das estruturas de aço. Entrevista de Novaes, F. F. Cimento Itambé, 2013.

[14] TAYLOR, H.F.W; FAMY, C; SCRIVENER, K.I. Delayed ettringite formation. Cement And Concrete Research, [s.I.], v. 31, n. 5, p. 683-693, May 2001. Elsevier BV. http://dx.doi.org/10.1016/s0008-8846(01)00466-5.

[15] WU, S.; HUANG, D.; LIN, F.; ZHAO, H.; WANG, P. Estimation of cracking risk of concrete at early age based on thermal stress analysis. Journal of Thermal Analysis and Calorimetry, v. 105, n. 1, p. 171-186, 2011. 